\title{
CA-informed Interactional Feature Analysis of Conversations in Textbooks Used for Teaching English Speaking in Thai Secondary Schools
}

\author{
Nasree Pitaksuksan ${ }^{1} \&$ Kemtong Sinwongsuwat ${ }^{2}$ \\ ${ }^{1}$ M.A. Student $\&{ }^{2}$ Assistant Professor Dr., Department of Languages and Linguistics, Faculty of Liberal Arts, \\ Prince of Songkla University, Hat Yai, Thailand \\ Correspondence: Nasree Pitaksuksan, Department of Languages and Linguistics, Faculty of Liberal Arts, Prince \\ of Songkla University, Hat Yai, Thailand
}

Received: May 12, 2020

Accepted: June 28, 2020

Online Published: June 29, 2020

doi: $10.5539 /$ elt.v13n7p140

URL: https://doi.org/10.5539/elt.v13n7p140

\begin{abstract}
With Conversation Analysis (CA) insights, this paper examines the textbooks used to teach oral English communication to Thai EFL learners in secondary schools. In an attempt to raise the awareness of features of naturally-occurring conversation and help increase the learners' exposure to these features, two textbook series, hereafter A and B, were purposively sampled for a close examination of their model conversations and related exercises. Six textbooks, three from each series, were obtained from secondary school teachers voluntarily joining a CA-informed English conversation-teaching workshop in lower southern Thailand. The findings showed that textbook series A contains action-driven, function-based communicative content, whereas B is theme/situation-based, being organized around topics or events likely faced by learners in daily life. Both textbook series put more focus on face-to-face dialogues, offering a significantly smaller number of phone and multi-party conversations. The model conversations in both series are presented with punctuation symbols of written language and without any representations of spoken language features such as stress and intonation. Some of the conversations in series B are sequentially incomplete, and while offering students conversations with various types of action sequences, both series can integrate more opening and closing sequences as well as sequences with dispreferred responses into their model conversations. To raise learners' awareness of features of natural conversation, more instances of repair and overlap may also be integrated into both audio and printed materials. Finally, to achieve the communicative unit goal, more scaffolding exercises can be provided to allow students to practice not only word and sentence pronunciation in isolation, but in relation to achieving a particular interactional goal via the construction of turns in more manageable, meaningful sequences.
\end{abstract}

Keywords: Conversation Analysis (CA), English conversation features, English conversation textbooks, EFL learners, textbook analysis, Thai high school Students

\section{Introduction}

English is one of the main subjects that have been set in the Basic Education Core Curriculum for Thais to study from the beginning of their formal education. Yet, Thai students are often ranked the lowest among those of Southeast Asian countries on the English proficiency scale, especially in speaking skills. (Education First, 2019; Khamkhien, 2010; Prapphal, 2001; WhereisThailand.info, 2012). Education First (2019) reported that Thais scored 47.61 out of 100 in its proficiency test. Similarly, Nation (2019) found that Mattayom 6 students who took the communicative part of the English subject in the Ordinary National Educational Test (O-NET) in the 2019 academic year scored an average of 29.40 out of 100, the lowest among all the subjects tested by the National Institute of Educational Testing Service (NIETS) (Nation, 2019).

Many solutions were proposed to improve the assessment results of Thai students' English proficiency. The Thai government has long endorsed Communicative Language Teaching (CLT) to address the problem. CLT aims to develop students' speaking ability via student-centered and task-based learning (Nonkukhetkhong, Baidauf Jr., \& Moni, 2006; Pusporini, 2009). In addition, more native English speaking teachers have been put in the English Program (EP) of public schools in order to increase chances for Thai students to interact daily in English. However, while trying to overcome the limitations of the traditional approach of pattern drills and rote memorization blamed 
for producing learners with low language accuracy and limited conversation performance (Saengboon, 2004), CLT implementation has never been easy for Thai practitioners. Mismatches have been reported between the CLT theory and actual practices in EFL settings like Thailand (Teng \& Sinwongsuwat, 2015). Thai students are notably more inclined towards being quiet and passive in the classroom (Wangkijichinda, 2011; Saengboon, 2002), relying on teachers being knowledge givers rather than facilitators. On the other hand, Thai teachers of English face challenges in developing activities and authentic materials that promote meaningful, goal-driven communication in student-centered classrooms (Nonkukhetkhong, Baidauf Jr., \& Moni, 2006).

In order to overcome the difficulties of both teachers and students in learning and teaching communicative lessons in Thai contexts, Conversation Analysis (CA), a sociological approach to studying everyday natural conversation, was integrated into lessons to improve L2 students' English communicative proficiency (Barraja-Rohan, 1997, 2011; Markee, 2009; Richards \& Seedhouse, 2005; Seedhouse, 2004, 2007; Wong \& Waring, 2010). CA was in fact used as a tool to dissect natural conversations for students, making them aware of sociocultural norms involved in their co-construction by talk participants (Baraja-Rohan, 1997, 2011; Markee, 2009; Wong \& Waring, 2010).

CA was credited with enhancing L2 learners' communicative ability via conversation lessons and performance assessment (Sitthikoson \& Sinwongsuwat, 2017; Tantiwich \& Sinwongsuwat, 2019; Teng \& Sinwongsuwat, 2015; Waedaoh \& Sinwongsuwat, 2017). However, English conversation textbooks, the key component in most language teaching programs, have yet to be analyzed with CA insights in order to get a clearer picture of their capacity to deliver accurate, genuine content of conversation in the target language lesson. As suggested in Kanoksilapatham (2007), to overcome communicative language teaching failures, it is vital to assist teachers in choosing materials that suit the English communication goal from the outset. In fact, studies show that mostly theme or situation-based EFL textbooks used in schools often failed to replicate conversations naturally occurring in everyday life. There are reports of textbooks used for teaching speaking which lack authentic input such as opening and closing sequences found in natural conversations (Bardovi et al., 1991; Grant \& Starks, 2001; Wong, 2007). The missing of pre-sequencing, which is an important element of natural conversation, was also noted (Bernsten, 2002). The textbooks used often provide model conversations with limited features of naturally occurring talk for students, thus decreasing their opportunity for exposure to actual conversation practices in real life (Waedaoh, 2018; Wong, 2007). Researchers therefore recommended that authentic spoken language data be integrated into conversation teaching materials (Burns, 1998; Carter \& McCarthy, 1997; McCarthy, 1991; Scotton \& Bernsten, 1988; Thornbury, 2005).

In an attempt to enhance the efficiency of EFL textbooks to maximize the students' exposure to the natural conversation in real life and to raise Thai EFL students' awareness of important features and mechanism of natural conversation believed to enhance their communicative ability, this study applies CA insights to investigating model conversations along with related exercises presented in textbooks designed for developing Thai secondary school students' speaking skills. It tries to reveal the missing features of naturally occurring conversation and to provide suggestions for enhancing the quality of model conversations presented by incorporating some of these features.

\section{Research Questions}

This paper addresses the following questions:

1) What are features of natural conversation that are missing from model English conversations and related exercises presented in textbooks used in Thai secondary schools?

2) What interactional features should be added to the textbooks to enhance efficacy in developing students' conversation abilities?

\section{Literature Review}

In recent years, the Thai government has touted Communicative Language Teaching (CLT) as one of the most desirable approaches to improving Thai students' English communication skills. However, it was never easy to implement this approach and deliver its promise, especially in the Thai context (Seangboon, 2004). There are often mismatches between theories and pedagogical practices in actual classrooms (Burns, 1998). While teachers are required to follow the foreign language curriculum set forth by the Ministry of Education, they are relatively free to design their own lessons appropriate for teaching communicative skills to students at each level. In practice, with constraints imposed by the entire education core curriculum, the emphasis in language teaching has often shifted towards preparing students for scoring well in O-NET and entrance examinations (Islam \& Bari, 2012), rather than enhancing their true communicative performance and equipping them with life-long skills. A survey of 
Chulalongkorn University Academic Services (2002) showed mismatches between the curriculum content and actual classroom practices due to the shifts in curriculum implementation. Additionally, Yunibandhu (2004) stated that it was often difficult for Thai teachers to engage students in communicative activities and maintain using natural English conversation in the classroom.

CA was recommended in order to overcome these mismatches between the core curriculum and actual classroom situations and maximize the opportunity for students to communicate in the target language in the classroom. CA is an approach to explicating natural talk, especially how speakers mutually manage their talk to get things done via its sequential organization (Seedhouse, 2005). It was applied to enhancing English conversation skills of Thai students. Shown in Markee (2005), CA gives learners a clear and extensive comprehension of the construct of conversation to produce more effective and comprehensible turns as outputs. Likewise, Barraja-Rohan (2011) indicated that students became successful in getting various views of language actions via CA-informed lessons. Applying CA insights to raising Japanese ESL students' awareness of language-specific aspects, Fuji (2012) also found that CA-based instruction increased the learners' interest in the mechanism of English conversational interaction while developing their interactional competence.

Investigating Thai non-English majors with elementary English proficiency (A2), Teng and Sinwongsuwat (2015), as well as Sitthaikoson(2017), confirmed positive results of integrating CA insights into CLT-oriented conversation lessons, with students in the experimental group receiving explicit CA informed instruction showing better communicative English performance and an increase in their confidence in both face-to-face and phone conversations. A subsequent study by Waedaoh (2018) recommended adding conversational materials such as sitcoms, movies and TV shows to enhance the effectiveness of CA-informed lessons. These materials increased Thai students' exposure to natural or near natural English, thereby enhancing their conversation abilities. As reported in the study, significant improvements in the students' conversation performance were observed in all the aspects assessed; a wider range of expressions were employed and the students were able to respond to turns more appropriately after training with CA-informed sitcom lessons. Sinwongsuwat, Nicoletti, and Teng (2018) also confirmed the necessity of equipping EFL learners with conversation analytical skills to become communicatively competent. Moreover, Tantiwich and Sinwongsuwat (2019) also concluded that CA could serve as a powerful analytic tool for identifying causes of problematic turns found in the learners' conversation.

Attempts have therefore been made in the Thai context to appeal to CA insights in enhancing the quality of English conversation teaching, diagnosing students' speaking problems, and uncovering methods to tackle these problems in an English conversation classroom (Sitthikoson \& Sinwongsuwat, 2017; Tantiwich \& Sinwongsuwat, 2019; Teng \& Sinwongsuwat, 2015; Waedaoh \& Sinwongsuwat, 2017). However, in order to increase the effectiveness of CA-informed communicative lessons in enhancing conversation abilities of Thai students, teaching materials like textbooks should also adequately capture the complexities of naturally occurring conversation via accurate representation, especially by containing genuine spoken language features found in real life communication. As Richards (2010) suggested, the content of lessons in a textbook should serve particular learners with different knowledge, and give teachers not only language content to teach, but also the way to teach it effectively.

It is vital to assist teachers in developing or selecting materials that match their objectives of developing students' natural conversation abilities in a particular context. However, it has been found that in reality EFL textbooks, which are mostly theme- or situation-based, contain model dialogs, which do not always provide an accurate representation of what people actually do in real life (Kanoksilapatham, 2007). Wong and Waring (2010) in particular stressed that conversation lessons should enable learners to not only construct and allocate turns in the target language but also understand what social actions the turns embody, especially what action to achieve through each turn in different social situations. Common actions done through turns at talk should also be made known to them such as greetings/leave-taking, agreement/disagreement, news announcements, compliment/response, invitation/decline, and apology since the understanding of these actions and how to respond to them is considered a crucial part of interactional competence (Sidnell, 2011; Wong, 2010).

Therefore, this study investigated the textbooks used in the classroom in order to enhance the capacity of CA-informed lessons in improving Thai students' English communicative performances. It will be easier for teachers to make their learners aware of the genuine nature of conversation that they will face in real life by presenting all the essential interactional features of natural conversation. This will also equip them with strategies for dealing with problems that may arise in real-time conversation.

\section{Methods}

This is a primarily qualitative study providing descriptive content analysis of model conversations presented in the contemporary English textbooks used for teaching secondary schools' students in southern Thailand. 


\subsection{Samples and Data Sources}

The sample series of the textbooks analyzed were purposively obtained from 16 secondary school teachers voluntarily joining a CA-informed English conversation-teaching workshop organized at the Faculty of Liberal Arts, Prince of Songkla University, Hat Yai, Thailand in June 2019. The teachers attending the workshop were from schools in the Secondary Education Service Area Offices 2 and 15, Narathiwat, Thailand. These teachers reported using two main series of English textbooks to teach English communication in their schools, conveniently referred to in the study as Textbook series $A$ and $B$. Both textbook series were authored by English native speakers and published by one of the major textbook distributors in Thailand. The two series were endorsed by the Thai government for the foreign language curriculum taught in secondary schools.

\subsection{1 "Textbook series A"}

This series consists of three textbooks used for teaching all skills of English and communicative skill of Matayom 1-3 (Grade 7-9). The books aim to promote active learning. The content is function-based, starting from basic conversation until advance interaction in daily life, such as introducing oneself until engaging in a job interview.

\subsection{2 "Textbook series B"}

This series is comprised of three textbooks used for teaching integrated skills of English to Matayom 1-3 students. The aim of the speaking section of these textbooks is to develop the conversation ability of the students according to various topics of talk. The content is about daily situations and some events that students might be facing in daily life, for example studying in school, going on vacation, and shopping at the mall.

The two series of textbooks serve as convenient and purposive samples for the case-study text analysis without the researcher's attempt to make statistical inferences in relation to larger collections of textbooks used in public secondary schools in other areas.

\subsection{Research Instruments}

In the study, the primary instrument was a CA-informed checklist of features of naturally occurring conversation, used by the researcher to identify the absence or presence of conversational features in the textbook samples of the study. It is a checklist which was created and validated by CA experts. Drawing on Schegloff \& Sack (1973), Schegloff (1986), as well as Wong \& Waring (2010), the checklist includes features of both face-to-face and phone interactional practices.

\subsection{Data Collection and Analysis}

\subsubsection{Determining General Features and Identifying Model Conversations along with Related Exercises}

After obtaining from the teachers the two main textbook series previously mentioned, the researcher examined the general features of the books to understand the purposes and their overall structure. Then, the model English conversations presented in each textbook along with related exercises were identified, and the exercises related to these model conversations were described according to their types and purposes.

\subsubsection{Identifying Missing Features and Categorizing them into Themes}

Ninety-three model conversations, 36 and 57 of which were respectively taken from textbook series A and textbook series B, were then analyzed using the CA-informed checklist of conversational features that had been validated. The checklist to examine face-to-face model conversations was comprised of four main practices/features: 1) turn-taking practice, involving the way in which turns are constructed and allocated (Ford, 2004; Ford \& Thompson, 1996; Fox, 1999 cited in Wong \& Waring, 2010); 2) sequencing practice, the way talk is sequentially organized while participants perform social actions such as requesting, inviting, story-telling or complaining (Schegloff, 1968); 3) overall structuring practice, the way in which a conversation is structured as a whole, including an opening, a centering and a closing ( Schegloff, 1968); and 4) repair practices, dealing with how problems in speaking, hearing, or understanding of talk are spotted and dealt with (Schegloff, 1977 cited in Wong \& Waring, 2010). On the other hand, the checklist for evaluating telephone conversations contained four additional features including: 1) summons-answer, requiring for opening up the channel of communication (Schegloff, 1968, 1986); 2) identification-recognition, completing identification of the parties involved (Schegloff, 1968, 1986); 3) greeting, a symbol of recognition (Schegloff, 1968); and 4) the How-are-you (HAY) sequence, which contains the question providing its recipient with a chance to convert her or his answer into the first topic of the interaction (Schegloff, 1968, 1986).

The findings from the textbook analysis was then categorized into different themes: the organization of the book, types of model conversations and related exercises provided, the presentation and representation of model conversations, as well as features of naturally occurring conversation missing from the model conversations and 
related exercises. In the end, suggestions were made with reference to the absent features that can possibly be added to the model conversations and their representations provided in the textbooks. Possible relevant conversational exercises were also recommended in order to help raise the awareness of the learners and engage them in the practices involved in constructing naturally occurring conversation.

\section{Results and Discussions}

The close examination revealed that both textbook series provide model samples of English conversations along with related exercises in every unit. In terms of the interactional content, the majority of the conversations provided in both series are face-to-face. Textbook series A offers function-based communicative content and each book in this series contains 10 conversations of which most are face-to-face, and only two are phone conversations. The two-party conversation model provided in each unit is organized around social actions such as greeting, talking about everyday life, giving directions, expressing feelings and opinion, making/declining an invitation, making an appointment, telling stories, reacting to news, applying for a job, and making an offer and each of these core actions produces sequences of eight turns on average.

Textbook series B, on the other hand, is theme-based, organized around topics in everyday life such as oneself, family and friends, indoor and outdoor activities, and social events. Each book in the series contains 12 units with two conversations each. More phone conversations are integrated into this series than in series A. Revolving around lives of five characters, each model conversation, both two and multiparty, takes place in one or more than one setting and it is goal-driven and situationally complete, rendering fairly long, complicated sequences with 14 turns on average. Apparently, Textbook series B focuses more on enlarging students' vocabulary and understanding of the conversation content rather than their ability to carry out complete, goal-driven conversations as shown in the model.

In the following, the two research questions posited above will be answered according to the main interactional features examined. Missing features from the model conversations and related exercises will be discussed in relation to the core interactional practices discretely examined using the checklist previously detailed. Concurrently provided below are also the recommendations for features to be added to the textbooks to raise Thai EFL students' awareness of interactional practices involved in the making of natural conversation, and to help enhance the efficacy of the textbooks in developing the students' abilities to converse in real life.

\subsection{Turn Construction and Allocation}

The transcripts of model conversations in both textbook series represent turn construction and allocation with punctuation symbols used in written language. Relying mainly on audio materials and teachers' pronunciation, the books provide transcripts of the model conversations without any representations of such important conversational features as stress, emphasis, and intonation to indicate how each turn should be phonetically and prosodically constructed. In addition, there was no video material accompanying the textbooks to make the students get a clearer understanding of the content of the conversations presented and to help them notice the way each turn is delivered. Both series of textbooks also did not highlight non-verbal language involved in the construction of the turn.

Regarding segmental and suprasegmental aspects of turn construction, textbook series A offers a separate section of a word-listening and pronunciation exercise targeting particular vowel or consonant sounds in every unit. Pairs of words, some of which are minimal pairs, show the contrast between selected sounds, and students are asked to listen to the sounds, repeat after the audio, and either identify words with the sounds heard or think of words with the same sounds. The sounds chosen include both single vowels such as /I/-/i:/ (e.g., pit-sleep), /ei/-/æa/ (e.g.,

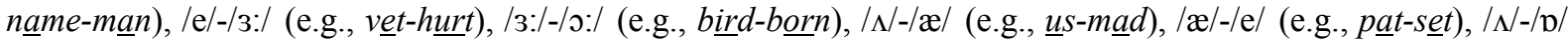

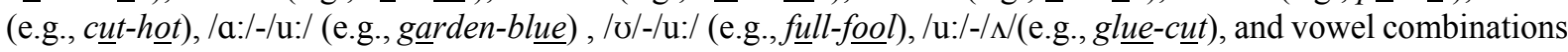
or glides such as /rə/ (e.g., near), /eə/ (e.g., fairy), /av/ (e.g., foul), and /ov/ (e.g., bone).

Consonant sounds mainly covered include those absent from the native language such as /è/-/ठ/ (e.g., tenth-the), /g/-/dz/ (e.g., garlic- large), and / / / (e.g., sheep), as well as those related to inflectional suffixes such as /s/-/z/-/Iz/ (e.g., speaks, goes, watch $\underline{\text { s }}$ ), /d///t/-/Id/ (e.g., played, walked, wanted), and /y/(e.g., cooking, eating). In each unit, only one pair of sounds is presented and the voiced vs. voiceless contrast is highlighted in consonant sounds, for instance, /s/-/z/ (e.g., face-please) and /f/-/v/ (e.g., fish-pery). The main purpose of the exercise apparently is to enable students to distinguish these sounds and pronounce them correctly.

Textbooks series B, on the other hand, offer fewer pronunciation exercises covering only certain vowels such as

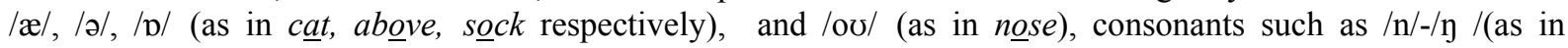

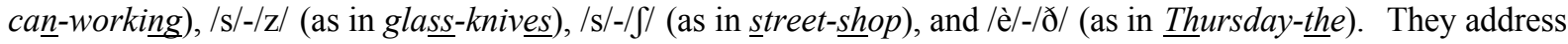


inflectional endings such as /d/-/t/-/rd/ (as in called, asked, chatted), /s/-/z/-/rz/ (as in likes, loves, teaches), and /rin/ (as in sitting). These sounds are distributed across different units and some units focus only on the pronunciation of inflectional suffixes such as $/ \mathrm{y} /$ (as in going). Similar to textbook series A, the pronunciation of the past-tense inflectional endings /d/, /t/, and /Id/ (as in played, walked, wanted) is also featured in Textbook series B even though series B appears to put more focus on sounds that are not present in Thai.

However, to help students master the pronunciation of English sounds, the exercises provided may also target sounds missing from the native language, not only in isolated words or sentences but also in meaningful sequences of turn construction. This will allow students not only to notice the differences between these sounds but also to produce them the way they should sound in actual conversations.

Additionally, even though pauses within turns and gaps between turns, pertinent to turn allocation, are very common in natural conversation, these features are not represented in any of the model conversations provided. Also ignored is overlap, another common mechanism in natural conversation. Nevertheless, although these features were absent in the transcripts provided in both series, moments of silence or pauses within and between turns are detectable to a certain extent in some of their audio-recorded conversations. Therefore, these conversational features should be made explicit in both transcribed and original conversations in order to raise the students' awareness of these aspects of natural talk.

\subsection{Sequential Structure}

In terms of the sequential structure of the model conversations presented, Textbook series A provides shorter, complete, and goal-driven dialogues, as shown in example 1 below.

Example 1: Textbook series A, M.1 (Grade 7), Unit 6

01 Matt: Hi, Jenny. Are you free this afternoon?

02 Jenny: Why?

03 Matt: Let's go shopping! I want to buy some new football boots.

04 Jenny: Sorry, I'm busy this afternoon. How about going tomorrow?

05 Matt: Sure, that's a good idea.

06 Jenny: OK, see you at 3 O'clock then.

(Virginia \& Jenny, 2014a, p. 64)

Textbook series B, on the other hand, offers both dialogues and multi-party conversations which are longer and some of which end abruptly with an incomplete sequence. Shown in Example 2, the conversation ends without a closing sequence on the current topic but a questioning first pair-part turn, which projects a missing second pair-part response as the current speaker, David, is shifting his talk to a different recipient. Without teachers' guidance, leaving a sequence opening like this may not aid students in developing their sense of sequence organization.

Example 2: Textbook series B, M.1(Grade 7), Unit 8

David calls the Info Point for Information.

01 Employee: Good morning, Info Point.

02 David: Hello, do you give information about museums?

03 Employee: Yes, we do. What do you want to know?

04 David: What time does the museum open?

05 Employee: The Natural History Museum opens at 9 o'clock.

06 David: No, the football museum.

07 Employee: I see... It opens at 10 o'clock... and it's free.

08 David: Great! Thank you very much!

09 David: OK, the Natural History Museum opens at 9, and the football museum

10 opens at 10. Which one do you want to go to?

11 Francesco: What do you think?

(Kavanagh et al., 2014a, p. 74) 
In addition, while offering several model conversations with various types of action sequences for students to learn, both series need to integrate more sequences with dispreferred responses into these model conversations. To help the students' master English conversation, it is very important to help them learn appropriate ways to deliver these types of responses. While preferred responses, i.e., those allowing the interactional goal of a particular previous turn to be accomplished, such as answering to a question, granting a request, and accepting an invitation, may be straightforward and easier to be dealt with, constructing dispreferred responses appears to be more challenging to most students (Hellerman, 2009).

In fact, Textbook series A provides only five model conversations with dispreferred responses in its entire series. For instance, students learn how to refuse appropriately an invitation with an appreciation preface such as thanks in one of the model conversations as seen below:

Example 3: Textbook A M.3 (Grade 9) Unit 3

01 Sam: Would you like to come with me?

02 John: Thanks, but I'm afraid I can't.

(Virginia \& Jenny, 2014b, p. 36)

Similarly, in Textbooks B, there were only two model conversations with dispreferred responses, also dealing with refusing an invitation. Therefore, to equip students with the ability to deliver appropriate dispreferred responses such as doing refusal and disagreement, the textbooks could integrate more examples of these responses into their model conversations.

\subsection{Overall Conversation Structure}

For EFL learners with little exposure to L2 conversation in daily life outside the classroom, to get in, carry on, and get out of the conversation is never an easy task (Shen \&Chiu, 2019). While any natural conversation has some form of opening, centering, and closing, sequences proven challenging for the learners to maneuver, such as opening and closing, do not always appear in the model conversations provided in the textbooks examined. Out of 36 model conversations presented in Textbook series A, six conversations do not contain opening sequences and seven were without closing sequences. On the other hand, almost half (27) and more than half (32) of the 57 model conversations provided in Textbook series B, revolving around lives of five characters, respectively lack opening and closing sequences.

Since it will be more likely for most EFL learners to use L2 to converse in unfamiliar contexts with people they do not know, it is necessary for them to know how to start and end a conversation appropriately (Wong \& Waring, 2010). It would therefore be beneficial to integrate more instances of opening and closing sequences into the model conversations presented and to vary the contexts in which these conversations take place and the participants involved in the conversations in each context.

\subsection{Repair Practice}

To be able to deal with problems in real talk, the students are supposed to be familiar with the repair mechanism. However, Textbook series A does not present examples of such a mechanism in any of its model conversations. Textbook series B, on the other hand, offers repair instances in some of their model conversations even though the amount of repair found is small, being detectable only on in four model conversations in the textbook for grade 7 students. The repair practices provided are of two types: other-initiated, self-repair and other-initiated, other-repair.

Shown in (4) below is an instance of other-initiated self-repair found in one unit of Textbook series B. There were only two instances found in the entire series. Notice that in line 01 David makes an incorrect identification of Francesco and Paolo. Therefore, Francesco corrects the misunderstanding in line 02, leading David to perform the repair by himself in line 03 .

Example 4: Textbook B M.1 (Grade 7) Unit 1

01 David: Hi, I'm David. Wow! You're identical. So, you're Paolo and you're Francesco!

02 Francesco: No, I'm Francesco and he's Paolo.

03 David: Oh, I'm sorry! You're Francesco and he's Paolo!

(Kavanagh et al., 2014a, p. 14) 
Textbook series B also offers an example of other-initiated other-repair in two of their model conversations. As shown in example 5, David asks Paolo a question, but the latter mishears its keyword. David spots the trouble and fixes it in the next turn in line 03, instantiating other-initiated, other-repair.

Example 5: Textbook B M.1 (Grade 7) Unit 2

01 David: How are you, Paulo? Are you hungry?

02 Paolo: I'm fine. I'm not angry! I'm happy to be here.

03 David: No, not angry! Hungry!

(Kavanagh et al., 2014a, p. 22)

Therefore, both textbook series could put emphasis on the repair mechanism of talk via a greater number of examples and other types of repair prevalent in naturally-occurring conversation, including self-initiated, self-repair, and other-initiated, self-repair (Fox, Maschler, \& Uhmann, 2010; Sinwongsuwat, 2018).

\subsection{Overall Provision of Exercises}

Apart from pronunciation exercises discussed earlier in relation to turn construction, both textbooks also provide other kinds of exercises, which allow students not only to understand the content of model conversations but also to practice different elements of a conversation. Textbook series A provides an exercise aimed at checking the students' comprehension of turns in the model conversation in every unit. The exercise asks them to find turns in the model conversation with the same meaning as the phrases given, allowing students to learn alternative ways of making particular turns with different expressions. However, students may still not be able to use them while making actual conversation if asked only to locate these turns.

The books also provide exercises for students to practice constructing turns on particular topics related to the content of the model conversation provided at the beginning of each unit. Students are asked in these exercises to pair up and create a dialogue to act out in different roles. For example, in one unit under the topic "Here you are!," they have to construct their own conversation in which one partner takes the role of a shop assistant and the other a customer who wants to change the clothes bought. However, examples of the conversation are provided in only two turns; therefore, students may need more scaffolding from the teacher to be able to construct a complete conversation to fulfill the assigned communication goal.

Textbook series B, on the other hand, provides a greater variety of exercises targeting both comprehension and production. The first exercise of each unit aims at checking comprehension of the model conversation content, in either the True (T) or False (F) or multiple-choice format. The next exercise under the topic "Sound Good" targets segmental and suprasegmental features of speech. Just as in series A, word pronunciation exercises provided in every unit allow students to practice distinguishing and pronouncing minimal pairs of contrastive sounds. However, unlike series A, exercises dealing with rising and falling intonation are also provided in some units with a representation of rising and falling symbols, appearing in sample sentences as shown in examples 6.1 and 6.2 below,

Example 6.1: Textbook B M.1(Grade 7) Unit 8

$$
\text { Are you hungry? }
$$

(Kavanagh et al., 2014a, p. 77)

Example 6.2: Textbook B M.3 (Grade 9) Unit 11

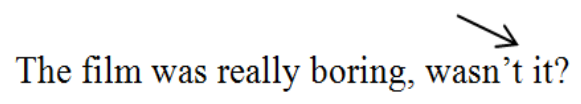

(Kavanagh et al., 2014b, p. 95) 
After these comprehension and pronunciation exercises, there is a turn and sequence production exercise titled "My Turns". The exercise provides students with a question prompt related with the topic of the unit and asks them to pair up to make a two-turn question-answer sequence in switched roles. In some units, the students are given turns to put in a correct order to make a 5-6 turn conversation to act out later. The last exercise of every unit in Textbook B, "Look \&Use," targets the grammatical aspect of turn construction, featuring the usage of grammatical items in the model conversation such as the use of tenses, question tags, and wh-questions.

The books in this series therefore provide exercises that highlight most of the important components of turn construction. However, similar to series A, in order to enable students to carry out a conversation to accomplish the communicative goal set for each unit, more scaffolding exercises should be provided which match the goal of the unit. The goal of these exercises should be to help students to practice constructing various types of turns and sequences via a greater variety of samples other than question-answer sequences.

\section{Conclusion and Recommendations}

This study undertook a CA-informed examination of model conversations and related exercises in the two sample textbooks designed for developing Thai secondary school students' speaking skills. It was found that both textbook series contained a significantly smaller number of phone than face-to-face conversations, most of which are two-party. No representations of spoken language features such as stress, intonation, pause, overlap and repair were provided in the transcripts of the model conversations presented. Only two types of repair practice were found in all the model conversations examined. Dispreferred responses to turns were not accentuated. Additionally, while highlighting key linguistic components involved in constructing L2 turns, both series offered few scaffolding exercises to aid the students in constructing natural, sequentially complete L2 conversation by themselves.

Consequentially, our recommendation is that the following features may be added to both textbooks to enhance the efficacy of the model conversations and exercises offered in helping students to develop English conversation skills. Namely, both textbooks can entertain more examples of phone and multi-party conversations to make students become aware of different types of conversation that they will face in everyday life. More instances of opening and closing sequences can also be integrated into the model conversations presented. In terms of sequential structure, model conversations presented should be sequentially complete to help students develop a sense of sequence organization in conversation. There should also be more examples of dispreferred responses since these types of responses are often challenging for EFL learners to master.

The study additionally recommends that stress and intonation be represented in the printed transcript to raise students' awareness of spoken language features. The textbooks should also present segmental features in an interactional context, rather than in isolated words and short phrases, allowing students to practice making conversation with the awareness of these features. In addition, overlap and repair should also be added both to the audio and to printed materials to make the model conversations sound and look more realistic, increasing the opportunity for the students to be exposed to essential features of natural or near-natural conversations. Finally, there should be scaffolding exercises that match the goal of the unit, especially in enabling learners to construct turns and carry out manageable conversation to accomplish their interactional goals.

\section{Acknowledgements}

The authors would like to offer special thanks to secondary school teachers voluntarily joining a CA-informed English conversation-teaching workshop organized at the Faculty of Liberal Arts, Prince of Songkla University, Hat Yai, Thailand in June 2019 for providing both textbook series as research samples.

\section{References}

Bardovi-Harlig, K., Hartford, B.A.S., Mahan-Taylor, R., Morgan, M.J., \& Reynolds, D.W. (1991). Developing pragmatic awareness: Closing the conversation. ELT Journal, 45(1), 4-15. https://doi.org/10.1093/elt/45.1.4

Barraja-Rohan, A. M. (1997). Teaching conversation and sociocultural norms with conversation Analysis. Australian Review of Applied Linguistics. Supplement Series, 14(1), 71-88. https://doi.org/10.1075/aralss.14.04bar

Barraja-Rohan, A. M. (2011). Using conversation analysis in the second language classroom to teach interactional competence. Language Teaching Research, 15(4), 479-507. https://doi.org/10.1177/1362168811412878

Bernsten, S. (2002). Using conversation analysis to examine pre-sequences in invitation, offer and request dialogues in ESL textbook [Master's thesis, University of Illinois]. https://eric.ed.gov/?id=ED469206 
Burns, A. (1998). Teaching speaking. Annual Review of Applied Linguistics, 18(1), 102-123. https://doi.org/10.1017/S0267190500003500

Chulalongkorn University Academic Service Centre. (2000). Report on the project to evaluate the development of education at the primary and secondary levels in government and private sectors-Science, Mathematics and English. Bangkok: CU Academic Service Centre.

Education First. (n.d). English proficiency Index. Retrieved March 2, 2020, From EF EPI reports. https://www.ef.com/media/centralefcom/epi/downloads/full-reports/ef-epi- 2019english.pdf

Ford, C. E. (2004). Contingency and units in interaction. Discourse Studies, 6(1), 27-52. https://doi.org/10.1177/1461445604039438

Ford, C. E., \& Thompson, S. A. (1996). Interactional units in conversation: Syntactic, intonational, and pragmatic resources for the management of turns. In E. Ochs, E. A. Schegloff, \& S. A. Thompson. (Eds.), Interaction and grammar (pp. 134-184). Cambridge: Cambridge University Press. https://doi.org/10.1017/CBO9780511620874.003

Fox, B., Maschler, Y. \& Uhmann, S. (2010). A cross-linguistic study of self-repair: Evidence from English, German, and Hebrew. Journal of Pragmatics, 42, 2487-2505. 10.1016/j.pragma.2010.02.006.

Fujii, Y. (2012). Raising awareness of interactional practices in L2 conversations: Insights from conversation analysis. International Journal of Language Studies, 6(3), 99-126.

Hellermann, J. (2009). Practices for dispreferred responses using "no" by a learner of English. International Review of Applied Linguistics in Language Teaching (IRAL), 47(1), 95-126. https://doi.org/10.1515/iral.2009.005

Islam, M. J., \& Bari, I. S. (2012). Implementation of CLT in Bangladesh and Thailand: Problems And challenges. Outlooks: VUB, 15(1), 87-105.

Kavanagh, F., Moore, C.L., Morris, C.E., Canaletti, E., Smith, A., \& Cattuna, J. (2014). Team up in English 1. Aksorn Charoen Tat ACT. Co., Ltd.

Kavanagh, F., Moore, C.L., Morris, C.E., Canaletti, E., Smith, A., \& Cattuna, J. (2014). Team up in English 3. Aksorn Charoen Tat ACT. Co., Ltd.

Khamkhien, A. (2010). Teaching English speaking and English-speaking test in the Thai context: A reflection from Thai perspective. English Language Teaching, 3(1). https://doi.org/10.5539/elt.v3n1p184

Kanoksilapatham, B. (2007). Navigating pathways to success in ELT. Journal of English studies, 3(1), 57-62.

Markee, N. (2005). Conversation analysis for second language acquisition. In E. Hinkel (Ed.) Handbook of research in second language teaching and learning (pp.355-374). Lawrence Erlbaum.

Markee, N. (2009). Conversation analysis. London, UK: Taylor \& Francis.

McCarthy, M. (1991). Discourse analysis for language teachers. Cambridge University Press.

McCarthy, M., \& Carter, R. (2014). Language as discourse: Perspectives for language teaching. Routledge. https://doi.org/10.4324/9781315845050

Ministry of Education. (2008). The basic education core curriculum.B.E. 2551.

Nation, T. (2019). Mathayom 6 students struggle in O-Net test. Retrieved March, 30, 2020, from http://www.nationmultimedia.com/news/national/30307964

Nonkululeko, K., Baldauf Jr., R. B., \& Moni, K. (2006, 19-21 January). Learner centeredness in teaching English as a foreign language [Paper presentation]. 26th Thai TESOL International Conference, Chiang Mai, Thailand.

Prapphal, K. (2003). English proficiency of Thai learners and directions of English teaching and learning in Thailand. Journal of Studies in the English Language, 1(2), 1-6.

Pusporini, N. (2009). A content analysis on English e-Book for junior high school GradeVII [S. Pd's Thesis University of Malang]. https://core.ac.uk/download/pdf/154750424

Richards, J. C. (2005). Communicative language teaching today. Cambridge University Press.

Richards, J. C. (2001). The role of textbooks in a language program. Cambridge University Press.

Saengboon, S. (2002). Beliefs of Thai EFL teachers about communicative language teaching [Doctoral 
dissertation, Indiana University Bloomington]. https://www.indiana.edu/research

Saengboon, S. (2004). Second language acquisition (SLA) and English language teaching (ELT). PASAA, 35(1), 11-34.

Schegloff, E. A. (1968). Sequencing in conversational openings. American Anthropologist, 70, 1075-95. https://doi.org/10.1525/aa.1968.70.6.02a00030

Schegloff, E. A., \& Sacks, H. (1973). Opening up closings. Semiotics, 8, 289-327. https://doi.org/10.1515/semi.1973.8.4.289

Schegloff, E. A, Jefferson, G., \& Sacks, H. (1977). The preference for self-correction in the organization of repair and conversation. Language, 53, 361-382. https://doi.org/10.2307/413107. https://doi.org/10.1353/lan.1977.0041

Schegloff, E. A. (1986). The routine as achievement. Human Studies, 9, 111-151. https://doi.org/10.1007/BF00148124

Schegloff, E. A. (2007). Sequence organization in interaction: A primer in conversation Analysis, 1. Cambridge: Cambridge University Press. https://doi.org/10.1017/CBO9780511791208

Scotton, C. M., \& Bernsten, J. (1988). Natural conversations as a model for textbook dialogue. Applied Linguistics, 9, 372-384. https://doi.org/10.1093/applin/9.4.372

Shen, M.Y., \& Chiu, T.Y. (2019). EFL learners' English-speaking difficulties and strategy use. Education and Linguistics Research, 5(2), 88-102. https://doi.org/10.5296/elr.v5i2.15333

Seedhouse, P. (2004). The interactional architecture of the language classroom: A conversation analysis perspective. Oxford: Blackwell.

Seedhouse, P. (2005). Conversation analysis and language learning. Language Teaching, 38(4), 165-187. https://doi.org/10.1017/S0261444805003010

Seedhouse, P. (2007). Interaction and constructions. In Z. Hua, P. Seedhouse, L. Wei, \& V. Cook (Eds.), Language learning and teaching as social inter-action (pp. 9-21). New York, NY: Palgrave Macmillan. https://doi.org/10.1057/9780230591240_2

Seedhouse, P. (2011). Conversation analytic research into language teaching andlearning. In E. Hinkel (Ed.), The handbook of research in second language teaching andlearning, (pp.345-363). London: Routledge.

Sidnell, J. (2011). Conversation analysis: An introduction (Vol. 45). John Wiley \&Sons. https://doi.org/10.1093/obo/9780199772810-0062

Sinwongsuwat, K. (2018). English written and spoken grammar: The essentials for second language teachers and learners. Kuala Lumpur, Malaysia: Nusa Centre \& Institute of Translation \& Books Malaysia (ITBM).

Sinwongsuwat, K., Nicoletti, K., \&Teng, B. (2018). CA-informed conversation teaching: Helping Thai students unpack English conversation to become conversationally competent. The Journal of Asia TEFL, 15(3), 700-720. https://doi.org/10.18823/asiatefl.2018.15.3.9.700

Sitthikoson, A., \& Sinwongsuwat, K. (2017). Effectiveness of explicit CA-informedtelephone conversation instruction in enhancing conversation abilities of Thailearners of English. Veridian E-Journal, 10(4), 63-85.

Tantiwich, K., \& Sinwongsuwat, K. (2019). Thai university students' use of yes/no tokens in spoken interaction. English Language Teaching, 12(3), 1-12. https://doi.org/10.5539/elt.v12n3p1

Teng, B., \& Sinwongsuwat, K. (2015). Teaching and learning English in Thailand and the integration of Conversation Analysis (CA) into the classroom. English Language Teaching, 8(3), 13-23. https://doi.org/10.5539/elt.v8n3p13

Thornbury, S., \& Slade, D. (2006). Conversation: From description to pedagogy. Cambridge University Press. https://doi.org/10.1017/CBO9780511733123

Tsang, W. K., \& Wong, M. (2002). Conversational English: An interactive, collaborative, and reflective approach. In J. C. Richards, \& W. A. Renandya (Eds.), Methodology in Language Teaching: An Anthology of Current Practice (pp. 212-224). Cambridge: Cambridge University Press. https://doi.org/10.1017/CBO9780511667190.029

Virginia, E., \& Jenny, D. (2014). Access 1. Aksorn Charoen Tat ACT. Co., Ltd.

Virginia, E., \& Jenny, D. (2014). Access 3. Aksorn Charoen Tat ACT. Co., Ltd. 
Waedaoh, A, \& Sinwongsuwat, K. (2018). Enhancing English language learners' conversation abilities via CA-informed sitcom lessons. English Language Teaching, 11(12), 121-130. https://doi.org/10.5539/elt.v11n12p121

Wangkijchinda, K. (2011). Developing intercultural communicative competence: A guide for English foreign language teachers in Thailand [Master's thesis, California State University, United States of America]. http://hdl.handle.net/10211.4/346

Wong, J. (2002). Applying conversation analysis in applied linguistics: Evaluating dialogue in English as a second language textbooks. IRAL, 40(1), 37-60. https://doi.org/10.1515/iral.2002.003

Wong, J. (2007). Answering my call: a look at telephone closings. In H. Bowles \& P. Seedhouse (Eds.), Conversation analysis and language for specific purposes (pp. 271-304). Bern: Peter Lang.

Wong, J., \& Waring, H. Z. (2010). Conversation analysis and second language pedagogy: A guide for ESL/EFL teachers. New York: Routledge. https://doi.org/10.4324/9780203852347

Yunibandhu, R. (2004). Problems faced by Thai students making the transition from the Thai school system to the international school system [Master's Thesis,Chulalongkorn University]. http://cuir.car.chula.ac.th/handle/123456789/2713

\section{Copyrights}

Copyright for this article is retained by the author(s), with first publication rights granted to the journal.

This is an open-access article distributed under the terms and conditions of the Creative Commons Attribution license (http://creativecommons.org/licenses/by/3.0/). 